\title{
Screening of Highly Efficient Fungi for the Degradation of Lignocelluloses by lonic Liquids-assisted Cellulase
}

\author{
Xiao-Mei Hu, ${ }^{\text {acc,1 }}$ Shi-Jia Dong,, a,b,1,* Hui-Ying Han, ${ }^{c}$ Yun-Fei Gao, ${ }^{\text {d }}$ and Bi-Xian Zhang ${ }^{\mathrm{d}}$ \\ A successful conversion of lignocellulosic biomass into biofuel could be \\ achieved through an ionic liquids (ILs)-pretreatment and an enzyme \\ saccharification. In this study, the fungal strains with high cellulase \\ productions were isolated and identified as Penicillium janthinellum $\mathrm{FHH} 1$ \\ and $P$. oxalicum FLY4. A high cellulase production was obtained at $\mathrm{pH} 4.0$ \\ and $30{ }^{\circ} \mathrm{C}$ for $P$. janthinellum $\mathrm{FHH} 1$ with corn stalk and beef extract for 9 \\ days and for $P$. janthinellum $\mathrm{FHH} 1$ with corn stalk and peptone for 7 days. \\ $\mathrm{A} \mathrm{pH}$ range between 4.0 to 6.0 and a temperature range from $55^{\circ} \mathrm{C}$ to 60 \\ ${ }^{\circ} \mathrm{C}$ were applicable for cellulase with high activities during hydrolysis. A \\ high $\mathrm{NaCl}$-stability and a relatively high ILs-stability were found for \\ cellulase obtained from $P$. oxalicum FLY4. High yields of reducing sugar \\ were obtained by enzymatic hydrolysis of the original corn stalk and ILs- \\ pretreated corn stalk. $P$. oxalicum FLY4 has a great potential for ILs- \\ assisted fungi in the degradation of lignocellulosic biomass into value- \\ added products.
}

DOI: 10.15376/biores.17.1.355-368

Keywords: Lignocelluloses; Ionic liquids; Fungi; Cellulase; Degradation

Contact information: a: Harbin University, Harbin, 150086, P.R. China; b: Heilongjiang Province Key Laboratory of Cold Region Wetland Ecology and Environment Research; c: Northeast Agricultural University, Harbin, 150030, P.R. China; d: Heilongjiang Academy of Agricultural Sciences, Harbin, 150086, P.R. China; *Corresponding author: huxiaomei1982@163.com; ${ }^{1}$ These authors contributed equally to this work.

\section{INTRODUCTION}

Lignocellulosic biomass is one of the most abundant and renewable resources on earth. The focus on the bioconversion of lignocellulosic biomass into biofuels has increased (Taha et al. 2015; Jatoi et al. 2021). Cellulose and hemicellulose, which comprise twothirds of lignocelluloses, are known as the main feedstock for biofuel production. The recalcitrant nature of lignocelluloses and the high crystallinity of cellulose limit the effective utilization of cellulosic biomass. An effective approach to convert cellulose into a valuable product is enzymatic saccharification (Pandey et al. 2000; Kirk et al. 2002). However, the low efficiency and the high cost of cellulase are still the main challenges faced (Baba et al. 2015).

Cellulase plays an important role in the release of monomeric sugars from cellulosic biomass. A complete cellulase system includes endoglucanase (EG), cellobiohydrolase $(\mathrm{CBH})$, and $\beta$-glucosidase (BGL). These enzymes hydrolyze the $\beta$-1,4-D-glucan bonds in the cellulose to release glucose, cellobiose, and oligosaccharides (Paramjeet et al. 2018). Numerous microbes, such as Trichoderma sp., Aspergillus sp., and Penicillium sp. are described as cellulase producers (Verma et al. 2010). Nevertheless, the lack of the complete 
cellulase reduces the hydrolysis efficiency; for instance, the lack of $\beta$-glucosidase of $T$. reesei lowers the enzymatic hydrolysis. Researchers have focused on the isolation of microbes with a high production of the complete cellulase to achieve the efficient cellulose digestibility (Dashtban and Qin 2012).

Due to the recalcitrant structure of lignocelluloses, the utilization of steam explosion, acid, alkaline conditions, or ionic liquids (ILs) as a pretreatment have been a requirement. The ILs have been considered as an efficient pretreatment solvent (Fitzpatrick et al. 2010). This solvent can decompose the complex structure of lignocelluloses and reduce the crystallinity of cellulose to improve the subsequent enzymatic hydrolysis. The combination of ILs-pretreatment and cellulase hydrolysis has potential to greatly improve the bioconversion of lignocelluloses.

In this study, a series of microbes were isolated and identified with two dominant cellulase-producing strains. Fermentation factors, including carbon, nitrogen, initial $\mathrm{pH}$, and fermentation time, were evaluated to improve the cellulase production. The $\mathrm{NaCl}$ stability and ILs stability of both microbes and cellulase were determined. The optimal $\mathrm{pH}$ and temperature of cellulase were studied for enzymatic hydrolysis. Enzymatic saccharification was investigated for corn stalk and ILs-pretreated corn stalk.

\section{EXPERIMENTAL}

\section{Sample Collection}

Soil samples were collected from the Greater Khingan Mountains (124.15951090674938E, 50.444505204846436N) in Heilongjiang province, China. Biomass was dried, ground, and passed through 40-mesh sieves. The chemicals pyridine (99\%), 1,4-dichlorobutane (99\%), 3-chloropropionic acid (99\%), and potassium hexafluorophosphate (99\%) were purchased from Aladdin Reagent Co., Ltd. (Shanghai, China).

\section{Screening of Cellulase-producing Microbes}

Each isolate was incubated on carboxyl methyl cellulose (CMC) medium including $\mathrm{K}_{2} \mathrm{HPO}_{4}\left(0.1 \%\right.$, weight per volume), $\mathrm{NaCl}\left(0.05 \%\right.$, weight per volume), $\left.\left(\mathrm{NH}_{4}\right)_{2} \mathrm{SO}_{4}\right)(0.2 \%$, weight per volume), $\mathrm{MgSO}_{4}(0.05 \%$, weight per volume), sodium carboxymethyl cellulose (CMC-Na) (1.0\%, weight per volume), and agar (1.0\%, weight per volume) at $30{ }^{\circ} \mathrm{C}$ for 5 days (Wood et al. 1988). After that, the plates were stained with Congo-red solution $(0.1 \%$, weight per volume) and were discolored with $1 \mathrm{~mol} / \mathrm{L} \mathrm{NaCl}$. One of the strains with a large hydrolysis zone was cultured in potato dextrose agar (PDA) medium including potato $(0.2 \%$, weight per volume), glucose $(0.02 \%$, weight per volume), and agar $(1.0 \%$, weight per volume) at $30{ }^{\circ} \mathrm{C}$ for 3 days (Xi et al. 2020).

A $1 \mathrm{~cm}$ agar piece was inoculated into potato dextrose (PD) medium including potato $(0.2 \%$, weight per volume), and glucose $(0.02 \%$, weight per volume). The solution was cultured at $30{ }^{\circ} \mathrm{C}$ and $150 \mathrm{rpm}$ for 3 days. A total of $1 \mathrm{~mL}$ of the suspension $(2 \%$, volume per volume) was added into $100 \mathrm{~mL}$ of Hutchinson medium including $\mathrm{NaNO}_{3}$ (0.25\%, weight per volume), $\mathrm{KH}_{2} \mathrm{PO}_{4}\left(0.10 \%\right.$, weight per volume), $\mathrm{MgSO}_{4}(0.03 \%$, weight per volume), $\mathrm{NaCl}\left(0.01 \%\right.$, weight per volume), $\mathrm{CaCl}_{2}$ (0.01\%, weight per volume), $\mathrm{FeCl}_{3}$ $(0.001 \%$, weight per volume) with corn stalk ( $1 \%$, weight per volume), and peptone $(0.2 \%$, weight per volume). The medium was incubated at $30{ }^{\circ} \mathrm{C}$ and $\mathrm{pH} 7.0$ and $150 \mathrm{rpm}$ for 5 
days. The solution was centrifuged at $4{ }^{\circ} \mathrm{C}$ with $10528 \mathrm{~g}$ for $10 \mathrm{~min}$ to provide the crude cellulase (Xi et al. 2020)

\section{Determination of Cellulase Activity}

The CMCase activity was measured with $1.5 \mathrm{~mL}$ of sodium carboxymethyl cellulose (1\%, weight per volume) and $0.5 \mathrm{~mL}$ of the crude cellulase at $50{ }^{\circ} \mathrm{C}$ for $30 \mathrm{~min}$. $\beta$-glucosidase activity was determined with $1.5 \mathrm{~mL}$ of salicin solution $(0.5 \%$, weight per volume) and $0.5 \mathrm{~mL}$ of the crude cellulase at $50{ }^{\circ} \mathrm{C}$ for $30 \mathrm{~min}$. Filter paper (FPase) activity was measured with $50 \mathrm{mg}$ of Whatman No. 1 filter paper $(1.0 \mathrm{~cm} \times 6.0 \mathrm{~cm})$ and $1.5 \mathrm{~mL}$ of sodium citrate buffer $(\mathrm{pH} 4.8)$ at $50{ }^{\circ} \mathrm{C}$ for $60 \mathrm{~min}$. The reducing sugars were determined by the 3,5-dinitrosalicylic acid (DNS) method (Miller 1959; Papa et al. 2017). One unit (U) of the cellulase activity was defined as the amount of the enzyme that released $1 \mathrm{mmol}$ of reducing sugar per min under the conditions indicated.

\section{Molecular Identification}

The DNA was extracted using a DNA kit based on the manufacturer's instructions (Omega BIO-TEC, Norcross, GA, USA). The universal primers ITS1 (5'-AGAAGTCGTAACAAGGTTTCCGTAGG-3') and ITS4 (5'-TCCTCCGCTTATTGATATGCTTAA$3^{\prime}$ ) were used for the polymerase chain reaction. The products were sequenced at the Huada Gene Company (Beijing, China). The phylogenetic tree was constructed using the Molecular Evolutionary Genetics Analysis (MEGA) program (version 11, Mega Limited, Auckland, New Zealand).

\section{Determination of Fermentation Factors}

The carbon source $(1 \%, \mathrm{w} / \mathrm{v})$ and nitrogen source $(0.2 \%, \mathrm{w} / \mathrm{v})$ were determined at $\mathrm{pH} 7.0$ for 5 days at $30{ }^{\circ} \mathrm{C}$ and $150 \mathrm{rpm}$ with $2.0 \%$ (volume per volume) of inoculation of strains. The fermentation time was examined at $\mathrm{pH} 7.0$ with corn stalk and peptone for the strain FLY4, and with corn stalk and beef extract for the strain FHH1. The initial pH was measured with corn stalk and peptone after 7 days for the strain FLY4. The initial pH was measured with corn stalk and beef extract after 9 days for the strain FHH1. The supernatant was obtained by centrifugation at $10,000 \mathrm{rpm}$ for $10 \mathrm{~min}$ for the determination of cellulase activity.

\section{Synthesis of Ionic Liquids}

Ionic liquids were synthesized according to Han et al. (2019). Pyridine (1.0 mmol) and 1,4-dichlorobutane $(1.0 \mathrm{mmol})$ were reacted at $60{ }^{\circ} \mathrm{C}$ for 4 days. The solid was purified by silica column chromatography $\left(\mathrm{CH}_{2} \mathrm{Cl}_{2} / \mathrm{MeOH}, 3 / 1\right)$ and was dried at $60{ }^{\circ} \mathrm{C}$ under vacuum for $4 \mathrm{~h}$. After that, the product $(1.0 \mathrm{mmol})$ was reacted with $\mathrm{KPF}_{6}(1.0 \mathrm{mmol})$ in deionized water at room temperature for $3 \mathrm{~h}$. The resulting product was dried in a vacuum for $12 \mathrm{~h}$. Following that, the product $(0.1 \mathrm{mmol})$ was reacted with pyridine $(0.12 \mathrm{mmol})$ at $80{ }^{\circ} \mathrm{C}$ for $24 \mathrm{~h}$. The resulting product was recrystallized with acetonitrile/ethyl acetate $(1 / 10)$ and was dried in a vacuum at $60{ }^{\circ} \mathrm{C}$ for $4 \mathrm{~h}$ to give hexafluorophosphate [1-(1pyridinium-yl- butyl)-4-pyridinium] chloride ([PF6] $\left.\left[(\mathrm{PYR}) \mathrm{C}_{4}(\mathrm{PYR})\right][\mathrm{Cl}]\right)$.

Pyridine $(0.2 \mathrm{~mol})$ was reacted with 3-chloropropionic acid $(0.2 \mathrm{~mol})$ at $70{ }^{\circ} \mathrm{C}$ for 24 h. After that, the product $(0.1 \mathrm{mmol})$ was reacted with hexafluorophosphate $(0.1 \mathrm{mmol})$ in $30 \mathrm{~mL}$ of deionized water at room temperature for $3 \mathrm{~h}$. The resulting solid was filtered and 
dried at $50{ }^{\circ} \mathrm{C}$ for $10 \mathrm{~h}$ to obtain [1-(2-carboxylpropyl)- pyridinium] hexaufluorophosphate $\left.\left((\mathrm{PYR}) \mathrm{C}_{2} \mathrm{COOH}\right]\left[\mathrm{PF}_{6}\right]\right)$.

\section{Determination of $\mathrm{NaCl}$ Stability and ILs Stability}

The optimal $\mathrm{pH}$ and temperature for the crude cellulase were measured in citrate buffer at $\mathrm{pH}$ values in a range of 3.0 to 11.0 and temperatures in a range of 30 to $70{ }^{\circ} \mathrm{C}$ for $1 \mathrm{~h}$. The stability of cellulase was measured in citrate buffer with the addition of $\mathrm{NaCl}$ or ILs at the optimal $\mathrm{pH}$ and temperature for different cellulase for $30 \mathrm{~min}$.

\section{Enzymatic Hydrolysis of Corn Stalk}

Corn stalk $(200 \mathrm{mg})$ was treated with $1.0 \mathrm{~g}$ of 1-(2-carboxylpropyl)-1-methylimidazolium hexafluorophosphate $\left(\left[\mathrm{MIMC}_{2} \mathrm{COOH}\right]\left[\mathrm{PF}_{6}\right]\right)$ and $3.0 \mathrm{~g}$ of hexafluorophosphate [1(1-pyridinium-yl-butyl)-4-methylimidazolium] chloride ([PF6][PYRC4MIM][Cl]) at 100 ${ }^{\circ} \mathrm{C}$ for $3 \mathrm{~h}$, followed by the addition of $1.5 \mathrm{~mL}$ of deionized water for $3 \mathrm{~h}$ (Han et al. 2019). The residue was filtered and washed with water. Following that, the residue was dried in a vacuum at $50{ }^{\circ} \mathrm{C}$ for $6 \mathrm{~h}$. The enzymatic reaction was performed with $100 \mathrm{mg}$ of the original corn stalk or ILs-pretreated corn stalk and $5 \mathrm{~mL}$ of the crude enzyme in $15 \mathrm{~mL}$ of citrate buffer with the addition of $200 \mu$ of $\mathrm{NaN}_{3}(10 \mathrm{mg} / \mu \mathrm{L})$ for $24,48,72$, and $96 \mathrm{~h}$. The reducing sugar was measured by the DNS method (Miller 1959; Papa et al. 2017). The yields of reducing sugar were determined as the ratio of the mass of reducing sugar in the mass of corn stalk or ILs treated corn stalk that was subjected to enzymatic hydrolysis according to Eq. 1.

$$
\text { Reducing sugar }(\%)=\frac{\text { Reducing sugar }(\mathrm{mg})}{\text { Corn stover or ILs treated corn stalk }(\mathrm{mg})} \times 100
$$

\section{Statistical Analyses}

Each experiment was performed in triplicate. The results are presented as mean values of three replicates with standard deviations (SD) shown as error bars. Statistical significance was determined by Student's t-test at significance levels indicated by asterisks as follows: ${ }^{*} \mathrm{p} \leq 0.05,{ }^{* *} \mathrm{p}<0.01,{ }^{* * *} \mathrm{p}<0.001$

\section{RESULTS AND DISCUSSION}

\section{Identification of Cellulase-producing Microbes}

A preliminary isolation of microbes was based on a Congo-red staining method. The isolates exhibiting clear hydrolytic zones were referred to as the potential cellulaseproducing microbes. Two predominant strains exhibited high enzymatic activities, indicating their strong cellulase-producing capability.

The ITS sequence of DNA was used for the identifications of fungal strains. The isolate FHH1 was identified as Penicillium janthinellum FHH1, as it showed 99\% similarity with Penicillium janthinellum (Fig. 1). The isolate FLY4 was identified as Penicillium oxalicum FLY4, as it showed 100\% similarity with Penicillium oxalicum. Numbers of strains of Penicillium sp., such as Penicillium janthinellum EMS-UV-8, Penicillium oxalicum JU-A10-T, and Penicillium oxalicum GZ-2 were reported as good cellulase producers (Singhania et al. 2014; Liao et al. 2014; Yao et al. 2015; Agrawal et 
al. 2017). The obtained nucleotide sequences were submitted to NCBI GeneBank under accession no. OK310849 for $P$. janthinellum FHH1 and OK310850 for P. oxalicum FLY4.

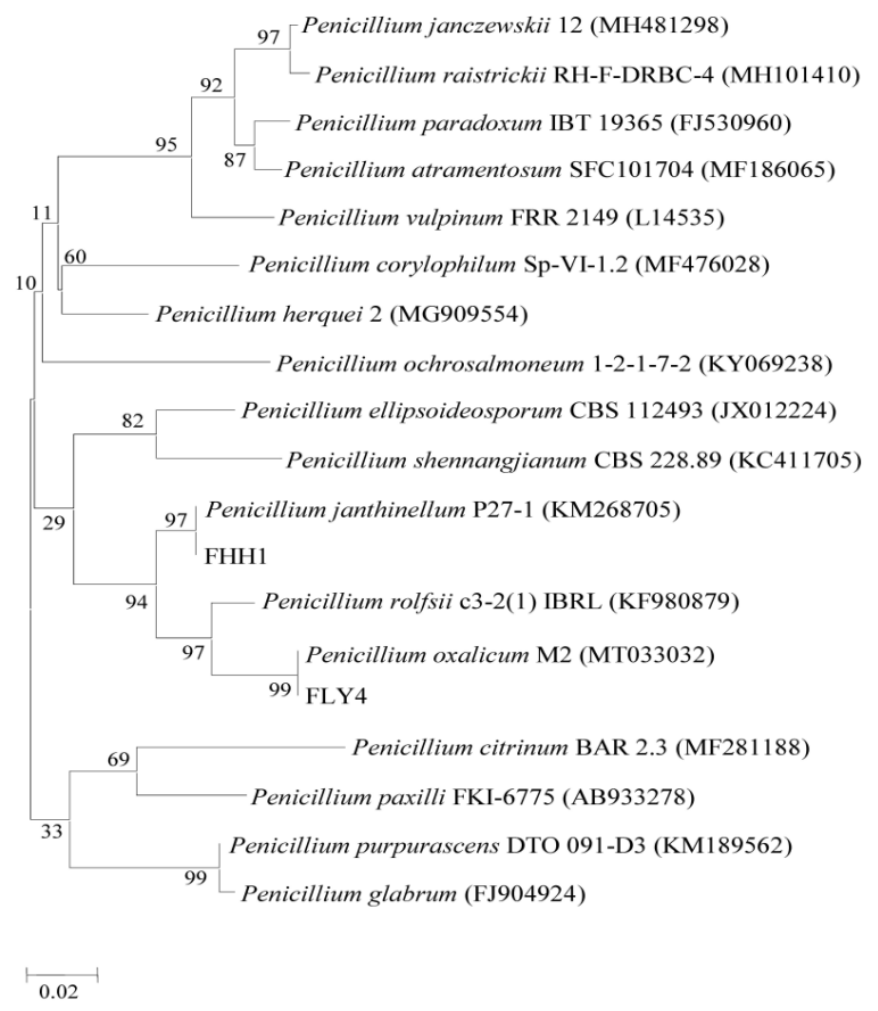

Fig. 1. The phylogenetic tree of the strains

\section{Enzyme Activity in Different Carbon Sources}

Carbon is a crucial nutrient for the growth and the reproduction of microbes. As shown in Fig. 2, corn stalk and rice straw were the effective carbon sources for $P$. janthinellum FHH1 and $P$. oxalicum FLY4. In particular, high productions of CMCase and $\beta$-glucosidase were observed with corn stalk as the carbon source. A high FPase production was obtained with rice straw as the carbon source. Nevertheless, low cellulase production was found with the utilization of $\mathrm{CMC}-\mathrm{Na}$ and cellulose. As cellulase-producing activity of the strain could be inducible by cellulosic biomass, high cellulase productions were obtained for $P$. janthinellum FHH1 and $P$. oxalicum FLY4 using corn stalk as enzymatic substrates.

Agricultural wastes exhibit cellulolytic enzyme inducible properties. As reported, higher cellulase activities were obtained for $P$. oxalicum GZ-2 when lignocellulosic biomass was used instead of commercial cellulose (Liao et al. 2015). Similarly, congress grass was used as good carbon source for Parthenium sp. with high xylanase production (Dwivedi et al. 2009). Rice straw and wheat straw were found to be the most effective for FPase production (Liao et al. 2015). Corn cob and oat husk were the best inducers of xylanase for Penicillium janthinellum (Oliveira et al. 2006). Therefore, agricultural residue is more efficient than purified cellulose at inducing lignocellulolytic enzyme production (Liao et al. 2014). The use of agricultural wastes has both economic and environmental advantages. 

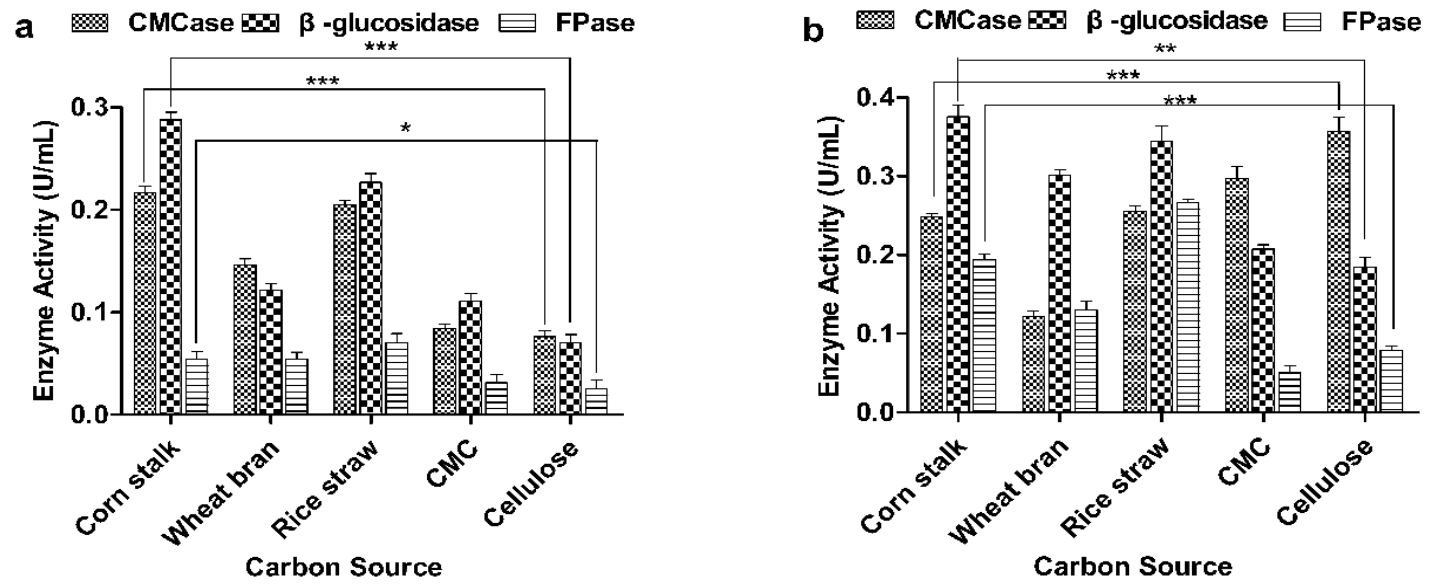

Fig. 2. Effect of carbon source on cellulase production: a) $P$. janthinellum $\mathrm{FHH} 1$ and b) $P$. oxalicum FLY4

\section{Enzyme Activity in Different Nitrogen Sources}

Nitrogen is a necessary nutrient for the growth of microbes, and it has an impact on their metabolic process. As presented in Fig. 3, high productions of CMCase, $\beta$ glucosidase, and FPase were observed with beef extract as the nitrogen source for $P$. janthinellum $\mathrm{FHH} 1$. Low cellulase productions were found with the utilization of $\mathrm{NH}_{4} \mathrm{NO}_{3}$ and urea.

In addition, peptone and yeast extracts were the effective nitrogen sources for $P$. oxalicum FLY4. Specifically, high productions of $\beta$-glucosidase and FPase were observed with peptone as the nitrogen source. A high production of CMCase was observed with yeast extract as the nitrogen source. Organic nitrogen on enzyme production was better than inorganic nitrogen for both strains. Therefore, beef extract was used for $P$. janthinellum FHH1 and peptone was used for P. oxalicum FLY4.
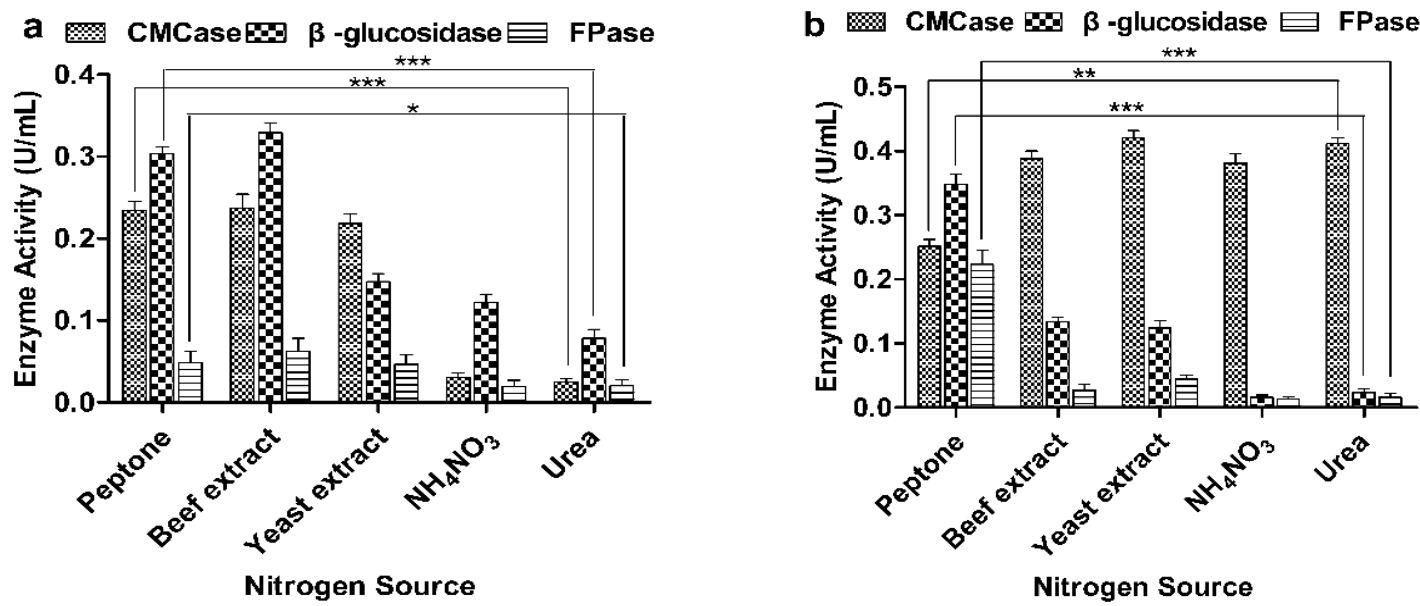

Fig. 3. Effect of nitrogen source on cellulase production: a) $P$. janthinellum $\mathrm{FHH1}$ and b) $P$. oxalicum FLY4 


\section{Enzyme Activity after Different Fermentation Time}

Cellulase production was improved with the increase of fermentation time (Fig. 4). A high yield of cellulase was obtained for $P$. janthinellum FHH1 after 9 days and for $P$. oxalicum FLY4 after 7 days. As the fermentation time increased, cellulase production was decreased due to the reduction and the depletion of nutrients. Moreover, the higher ratio of $\beta$-glucosidase and FPase of $P$. janthinellum FHH1 and $P$. oxalicum FLY4 was capable of improving the inhibition of enzymatic hydrolysis due to cellobiose accumulation.
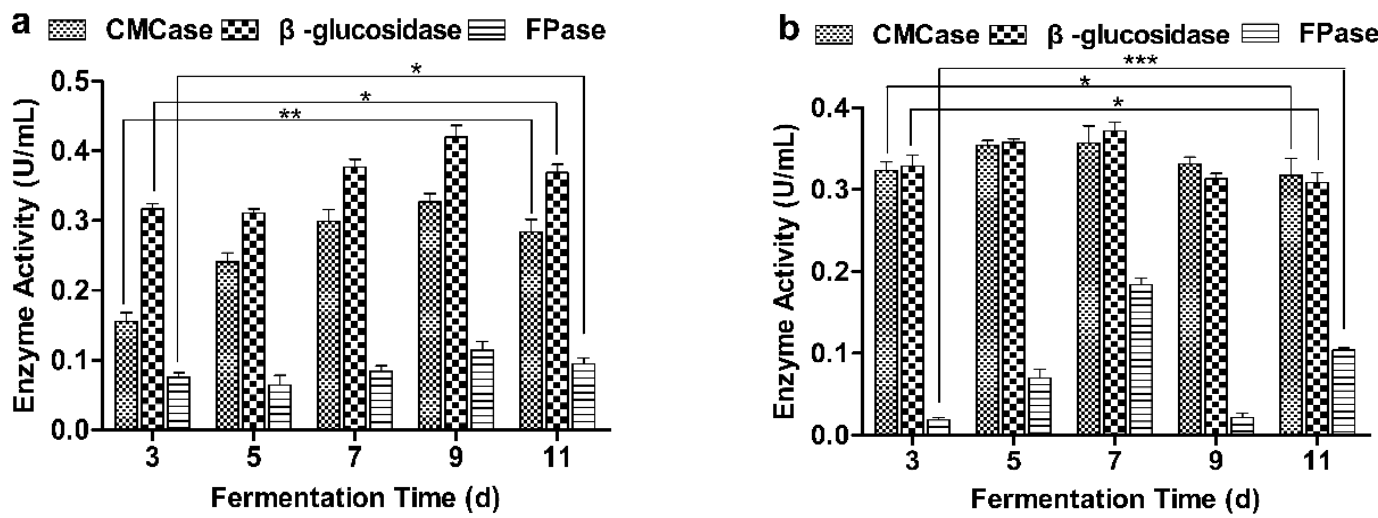

Fig. 4. Effect of fermentation time on cellulase production. a) $P$. janthinellum $\mathrm{FHH} 1$ and b) $P$. oxalicum FLY4

\section{Enzyme Activity at Different Initial pH}

Filamentous fungi have good growth over a broad range from $\mathrm{pH} 2$ to 9 with an optimal range from 3.8 to 6.0 (Gowthaman et al. 2001). P. janthinellum FHH1 preferred acidic $\mathrm{pH}$ conditions (3.0 to 5.0). Particularly, this strain possessed a high cellulase production at $\mathrm{pH}$ 9.0. In addition, a broad $\mathrm{pH}$ range from 3.0 to 11.0 was applicable for $P$. oxalicum FLY4 with pH 5.0 being optimal (Fig. 5). High production of CMCase and $\beta$ glucosidase was obtained at $\mathrm{pH} 7.0$ and $\mathrm{pH}$ 5.0, respectively.
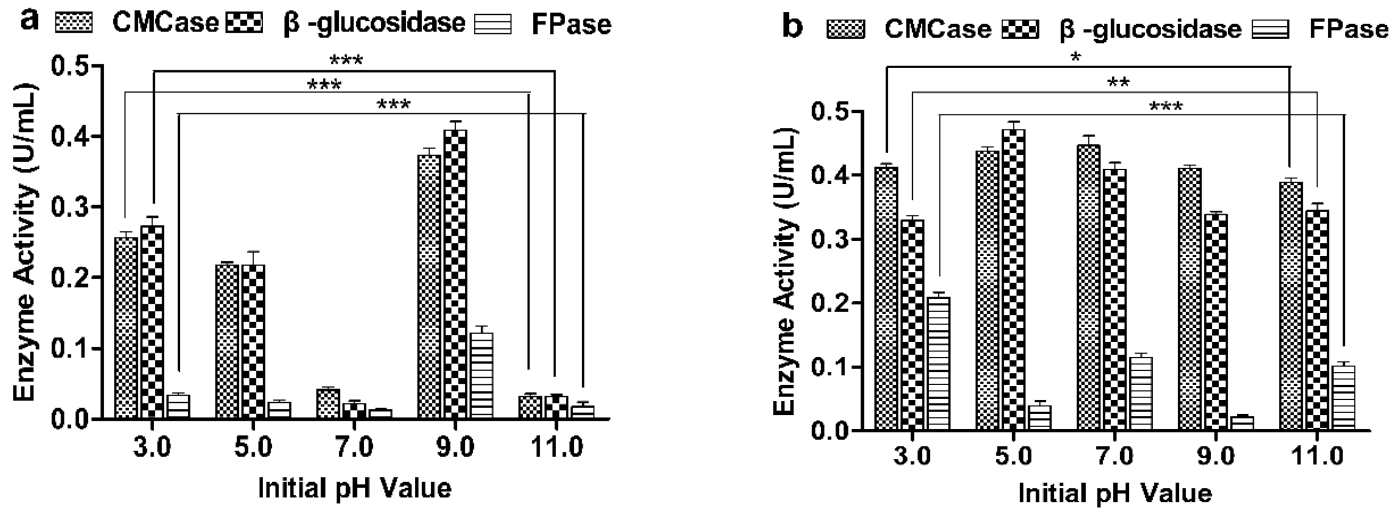

Fig. 5. Effect of initial $\mathrm{pH}$ value on cellulase production: a) $P$. janthinellum $\mathrm{FHH} 1$ and $b) P$. oxalicum FLY4

\section{pH Value on Cellulase Activity during Hydrolysis}

The $\mathrm{pH}$ value influences the stability of cellulase during the hydrolysis. Inappropriate $\mathrm{pH}$ may cause the destruction of the spatial structure and the dissociation 
state of the enzyme (Adsul et al. 2007). A pH value between 3.0 and 6.0 was applicable for cellulase of $P$. janthinellum FHH1 (Fig. 6). High activities of CMCase and $\beta$ glucosidase were obtained at $\mathrm{pH}$ 4.0. A high FPase activity was observed at $\mathrm{pH}$ 5.0. Meanwhile, a $\mathrm{pH}$ value from 4.0 to 6.0 was applicable for $P$. oxalicum FLY4 with $\mathrm{pH} 4.0$ being optimal for CMCase, $\beta$-glucosidase, and FPase. The CMCase and $\beta$-glucosidase of P. oxalicum GZ-2 showed remarkable stability in the $\mathrm{pH}$ range 4.0 to 9.0 and $\mathrm{pH} 3.0$ to 7.0 with $80 \%$ of the maximum activity (Liao et al. 2015). Optimum $\mathrm{pH}$ for activity of the crude enzyme of Penicillium oxalicum IODBF-5 were pH 5 (Saini et al. 2015). Thus, an acidic condition was preferred for $P$. janthinellum FHH1 and $P$. oxalicum FLY4 in this study.
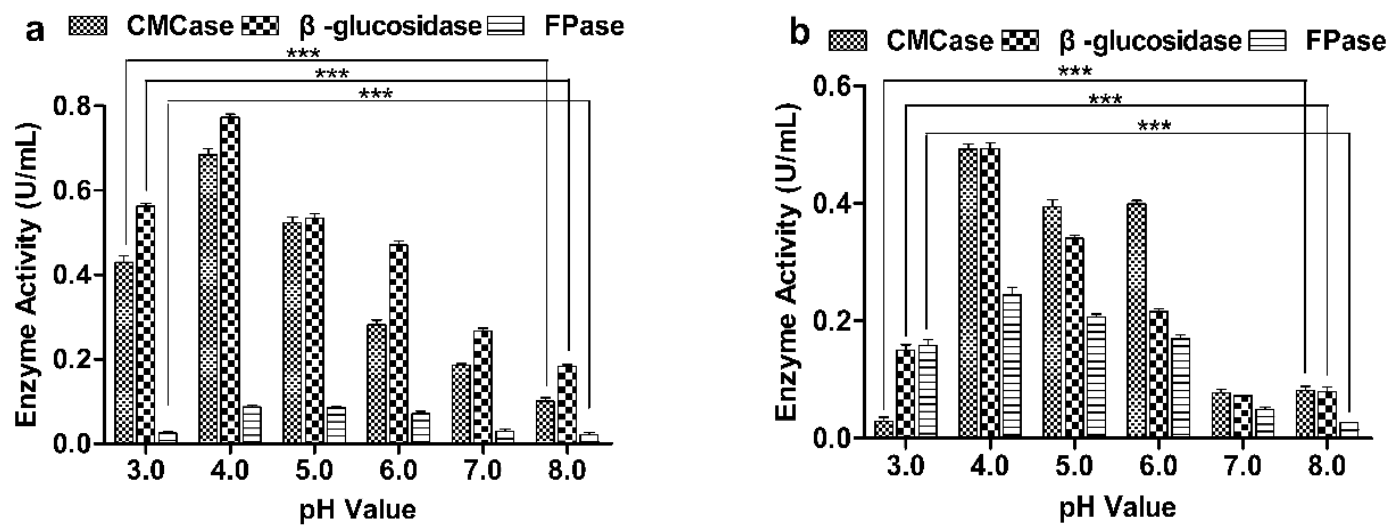

Fig. 6. Effect of $\mathrm{pH}$ value on cellulase activity: a: P. janthinellum $\mathrm{FHH} 1$; b: P. oxalicum FLY4

\section{Hydrolysis Temperature on Cellulase Activity}

A low temperature may decrease the rate of enzymatic reaction, while a high temperature may denature the protein leading to the loss of enzyme activity (Larsson et al. 2001). As the temperature was increased, the activities of $\beta$-glucosidase and CMCase for $P$. janthinellum FHH1 were improved with the maximum activity at 60 and $50{ }^{\circ} \mathrm{C}$, respectively (Fig. 7).
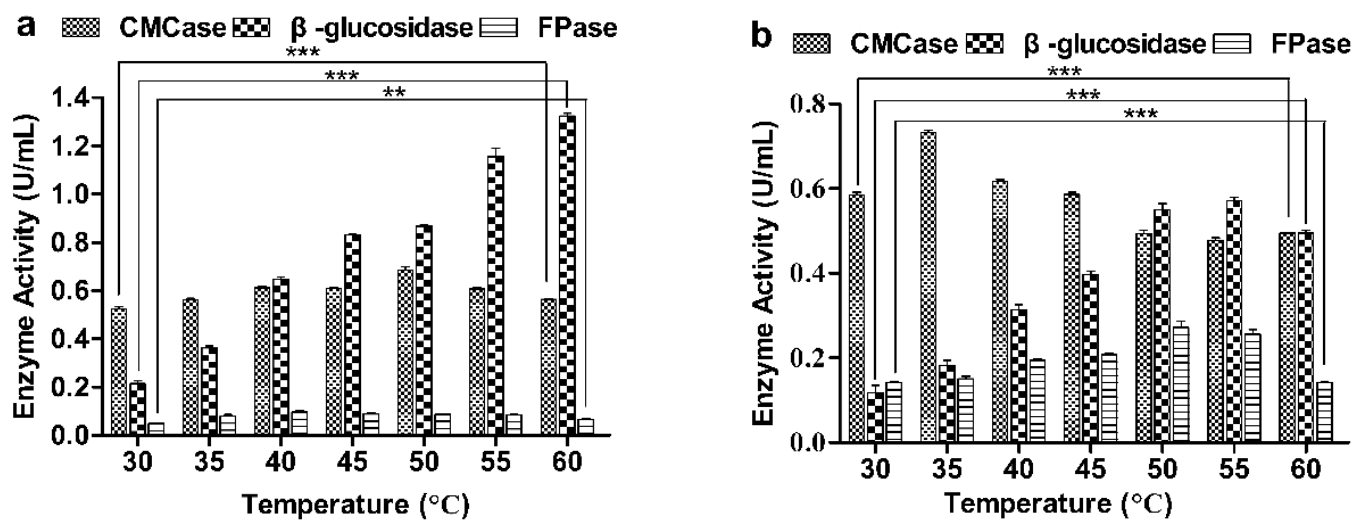

Fig. 7. Effect of hydrolysis temperature on cellulase activity: a) $P$. janthinellum $\mathrm{FHH} 1$ and b) $P$. oxalicum FLY4

No obvious reduction of FPase activity was found with the temperature variation. As reported, the optimal temperatures for CMCase and $\beta$-glucosidase activity were at 50 
and $60{ }^{\circ} \mathrm{C}$, respectively (Liao et al. 2015). The optimum temperature for activity of the crude enzyme of Penicillium oxalicum IODBF-5 were $50{ }^{\circ} \mathrm{C}$ (Saini et al. 2015). A high temperature was found for CMCase and $\beta$-glucosidase of $P$. janthinellum $\mathrm{FHH} 1$. Meanwhile, when the temperature was increased, the activities of $\beta$-glucosidase and FPase for $P$. oxalicum FLY4 were improved with the maximum activity at 55 and $50{ }^{\circ} \mathrm{C}$, respectively. However, the optimal temperature was found at $35^{\circ} \mathrm{C}$ for CMCase of $P$. oxalicum FLY4. Thus, CMCase activity was reduced with the increase of the temperature.

\section{$\mathrm{NaCl}$ Stability of Cellulase}

When $\mathrm{NaCl}$ concentration was increased from $2.5 \%$ to $7.5 \%$ (weight per volume), $\mathrm{NaCl}$ stability of CMCase was improved for P. janthinellum FHH1 (Fig. 8). No obvious reduction of FPase stability was found. Nevertheless, the stability of $\beta$-glucosidase was reduced with the increase of $\mathrm{NaCl}$ concentration.

Moreover, an improved CMCase activity was achieved for P. oxalicum FLY4 in a range from $25 \%$ to $35 \%(\mathrm{w} / \mathrm{v})$ of $\mathrm{NaCl}$ concentration with the maximum CMCase activity at $15 \%(\mathrm{w} / \mathrm{v}) . \mathrm{NaCl}$ precipitated out of the solution at $40 \%(\mathrm{w} / \mathrm{v})$. A slight reduction of the stability of $\beta$-glucosidase and FPase was found with the increase of $\mathrm{NaCl}$ concentration. Therefore, a high $\mathrm{NaCl}$ stability was achieved for P. oxalicum FLY4.
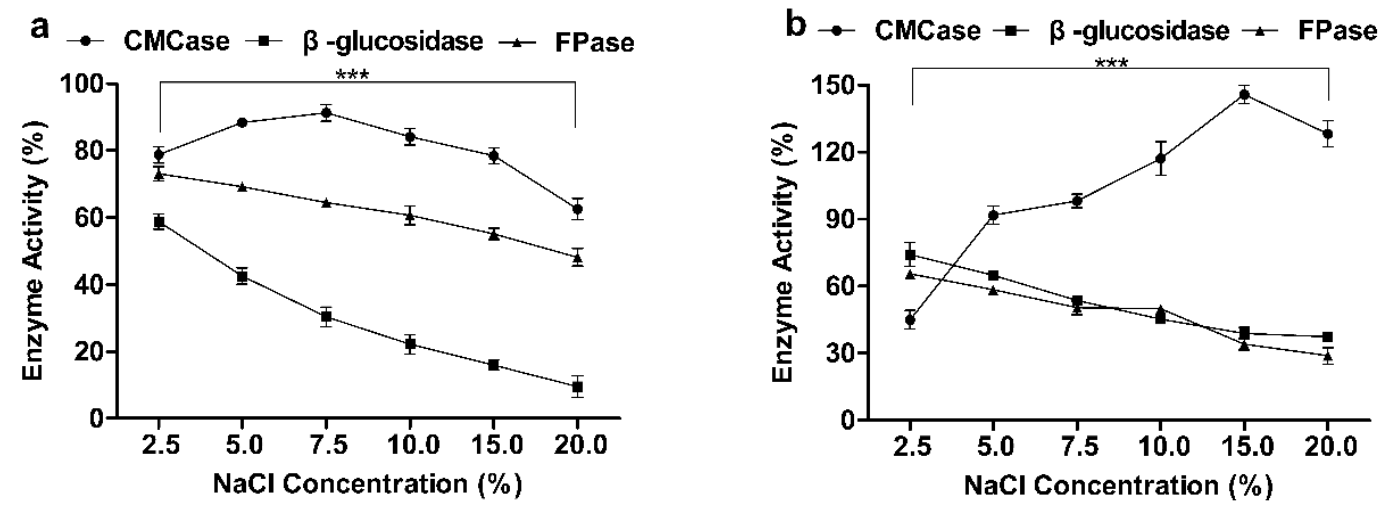

Fig. 8. NaCl-stability of cellulase. a: P. janthinellum FHH1; b: P. oxalicum FLY4

\section{ILs Stability of Cellulase}

A higher ILs stability was achieved with cellulase obtained from P. oxalicum FLY4 than that of P. janthinellum FHH1 (Fig. 9). A total of $66 \%$ and $63 \%$ of the CMCase activity was retained for $P$. oxalicum FLY4 with the addition of $2.5 \%(\mathrm{w} / \mathrm{v})$ of $\left[(\mathrm{PYR}) \mathrm{C}_{2} \mathrm{COOH}\right]\left[\mathrm{PF}_{6}\right]$, and $\left[\mathrm{PF}_{6}\right]\left[(\mathrm{PYR}) \mathrm{C}_{4}(\mathrm{PYR})\right][\mathrm{Cl}]$, respectively. A total of $57 \%$ and $51 \%$ of the CMCase activity was retained for $P$. janthinellum FHH1 with $\left[(\mathrm{PYR}) \mathrm{C}_{2} \mathrm{COOH}\right]\left[\mathrm{PF}_{6}\right]$, and $\left[\mathrm{PF}_{6}\right]\left[(\mathrm{PYR}) \mathrm{C}_{4}(\mathrm{PYR})\right][\mathrm{Cl}]$, respectively. The stability of $\mathrm{CMCase}$ was higher than $\beta$-glucosidase. It was reported that $\beta$-glucosidase was more stable than CMCase for P. janthinellum mutants, as CMCase showed $90 \%$ of its initial activity in $10 \%$ of 1-butyl-3-methylimidazolium chloride $([\mathrm{bmim}] \mathrm{Cl})$ and $\beta$-glucosidase retained $85 \%$ of its original activity in $30 \%$ of ionic liquid (Adsul et al. 2009). In addition, CMCase that was obtained from $P$. oxalicum FLY4 retained $86 \%$ of the original activity with [EMIM] $\mathrm{CH}_{3} \mathrm{COOH}$. A higher stability was found with [EMIM] $\mathrm{CH}_{3} \mathrm{COOH}$ for both strains. 

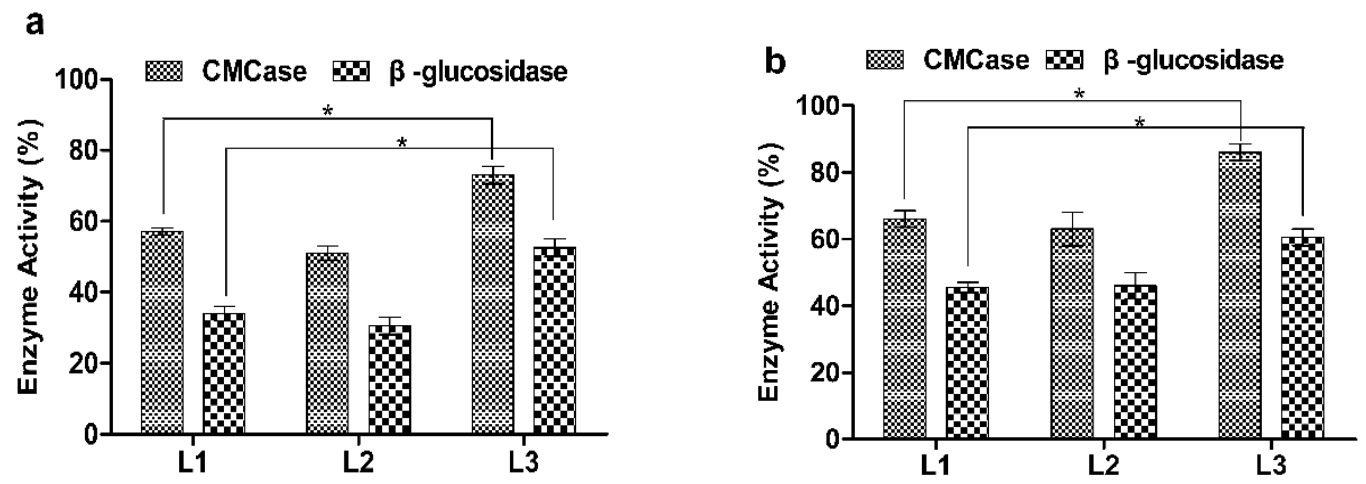

Fig. 9. ILs stability of cellulase: a) $P$. janthinellum $\mathrm{FHH1}$ and b) $P$. oxalicum FLY4; L1: [(PYR $\left.\mathrm{C}_{2} \mathrm{COOH}\right][\mathrm{PF} 6]$, L2: $\left[\mathrm{PF}_{6}\right]\left[(\mathrm{PYR}) \mathrm{C}_{4}(\mathrm{PYR})\right][\mathrm{Cl}]$ and L3: [EMIM] $\mathrm{CH}_{3} \mathrm{COOH}$

\section{Enzymatic Hydrolysis of Corn Stalk}

The enzymatic reaction was performed with $100 \mathrm{mg}$ of the original corn stalk and $5 \mathrm{~mL}$ of the crude cellulase for 24, 48, 72, and $96 \mathrm{~h}$ at $\mathrm{pH} 4.0$ for $P$. janthinellum $\mathrm{FHH} 1$. The temperature conditions varied at $60{ }^{\circ} \mathrm{C}$ for $\mathrm{FHH} 1$ and $35^{\circ} \mathrm{C}$ for $P$. oxalicum FLY4. As the hydrolysis time was increased from 24 to $96 \mathrm{~h}$, the reducing sugars yield was improved for both of strains. After $96 \mathrm{~h}$, the reducing sugars yield was $18 \%$ for P. janthinellum FHH1 and $33.75 \%$ for $P$. oxalicum FLY4. A higher performance of cellulase of $P$. oxalicum FLY 4 was achieved than that of $P$. janthinellum FHH1 (Fig. 10). Compared with acid pretreated and steam exploded wheat straw, the untreated wheat straw could be a good carbon source for the production of quality cellulolytic enzymes by $P$. janthinellum EMS-UV-8 mutant (Sharma et al. 2015). This is different with $P$. janthinellum FHH1 and $P$. oxalicum FLY4, because high hydrolysis efficiency was observed with ILs-pretreated corn stalk.
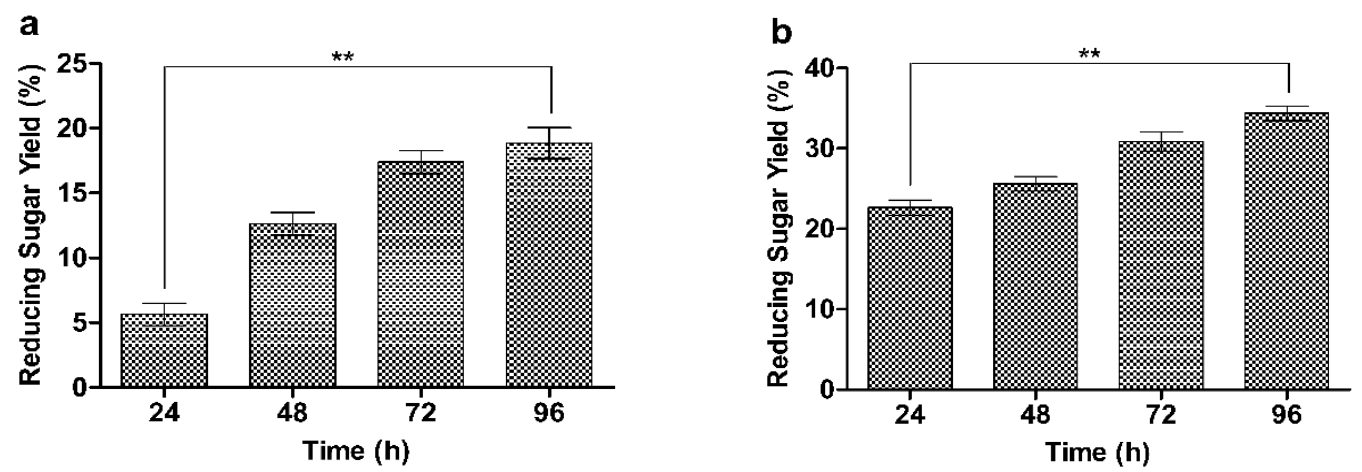

Fig. 10. Enzymatic hydrolysis of corn stalk: a) $P$. janthinellum $\mathrm{FHH} 1$ and b) $P$. oxalicum FLY4

\section{Enzymatic Hydrolysis of ILs-pretreated Corn Stalk}

During the treatment by the mixture of $\left[\mathrm{PF}_{6}\right]\left[(\mathrm{PYR}) \mathrm{C}_{4}(\mathrm{PYR})\right][\mathrm{Cl}]$ and $\left[(\mathrm{PYR}) \mathrm{C}_{2} \mathrm{COOH}\right]\left[\mathrm{PF}_{6}\right]$ at $100{ }^{\circ} \mathrm{C}$, a high reducing sugar yield for corn stalk was achieved at $18.80 \%$ (Han et al. 2019). The residue was obtained at $68.75 \%$ after ILs treatment. The enzymatic reaction was conducted with $100 \mathrm{mg}$ of ILs-pretreated corn stalk and $5 \mathrm{~mL}$ of the crude cellulase for 24, 48, 72, and $96 \mathrm{~h}$ for $P$. janthinellum $\mathrm{FHH} 1$ at $\mathrm{pH} 4.0$ and $60{ }^{\circ} \mathrm{C}$ and for $P$. oxalicum FLY4 at pH 4.0 and $35^{\circ} \mathrm{C}$. The reducing sugar yield increased with the increase of hydrolysis time (Fig. 11). After 96 h, the reducing sugar yield was $30.93 \%$ 
for $P$. janthinellum FHH1. A high yield was achieved of $52.37 \%$ for P. oxalicum FLY4 after $72 \mathrm{~h}$. Meanwhile, the yield of the reducing sugar was $42.21 \%$ for [EMIM] $\mathrm{CH}_{3} \mathrm{COOH}-$ pretreated corn stalk. Hydrolysis of acid or alkali-pretreated rice straw using cellulase enzyme preparations from $P$. janthinellum and $T$. reesei released $37 \%$ and $43 \%$ glucose, respectively (Sreeja-Raju et al. 2020). A crude enzyme solution of P. oxalicum Z1-3 was able to hydrolyze $92.5 \%$ of $\mathrm{KOH}$-pretreated sugarcane bagasse to glucose within $96 \mathrm{~h}$ (Jing et al. 2015). A crude enzyme solution of Penicillium oxalicum EU2106 was able to hydrolyze $94.3 \pm 1.5 \%$ of $\mathrm{NaOH}-\mathrm{H}_{2} \mathrm{O}_{2}$-pretreated cassava residue to glucose under solidstate fermentation for $96 \mathrm{~h}$ ( $\mathrm{Su}$ et al. 2017). In the present work, a high production of reducing sugar was achieved with the hydrolysis of $\left[\mathrm{PF}_{6}\right]\left[(\mathrm{PYR}) \mathrm{C}_{4}(\mathrm{PYR})\right][\mathrm{Cl}]$ / $\left[(\mathrm{PYR}) \mathrm{C}_{2} \mathrm{COOH}\right]\left[\mathrm{PF}_{6}\right]$-pretreated corn stalk by cellulase obtained from $P$. oxalicum FLY4.
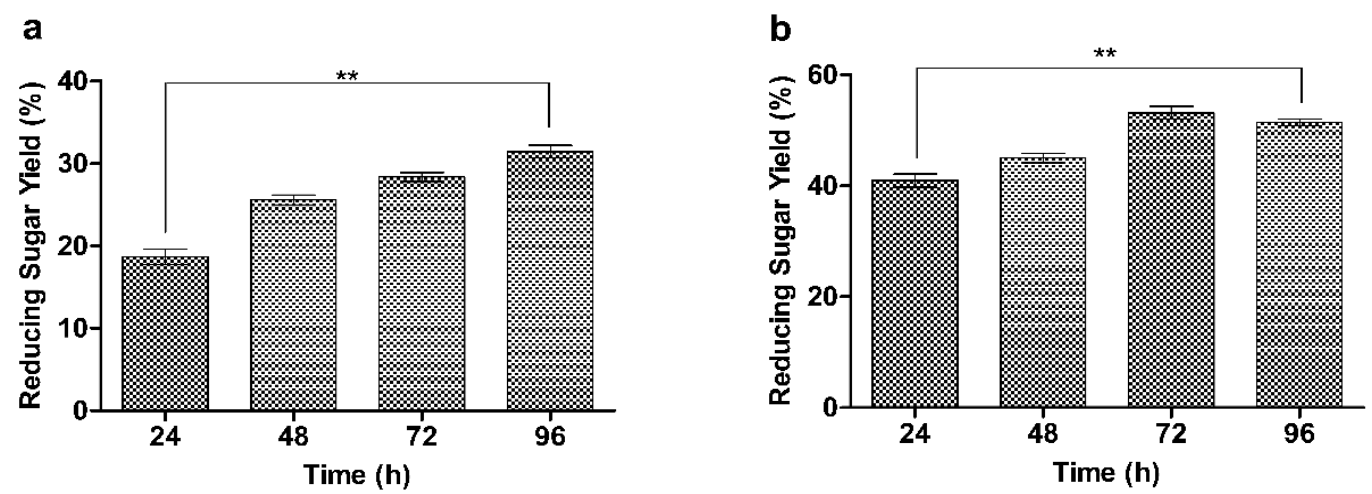

Fig. 11. Enzymatic hydrolysis of ILs-pretreated corn stalk: a) $P$. janthinellum $\mathrm{FHH} 1$ and b) $P$. oxalicum FLY4

Herein, cellulases from $P$. janthinellum FHH1 and $P$. oxalicum FLY4 have been successfully used for saccharification of corn stalk. Both of the strains from Penicillium species exhibit remarkable saccharification performance for supplementation of $\beta$ glucosidase-deficient Trichoderma cellulases (Gusakov and Sinitsyn 2012). Agricultural wastes act as non-food resource to save costs of the enzyme production process. In addition, the acidic group $\left(\mathrm{COOH}^{-}\right)$of ILs assists the hydrolysis of hemicellulose and cellulose of corn stalk. The anion $\left(\mathrm{Cl}^{-}\right)$of ionic liquids made it more effective at disrupting inter- and intra-molecular hydrogen bonding in lignocelluloses. Thus, the effective ILs-treatment of lignocelluloses contributed to achieve the high enzymatic digestibility. These cellulases from $P$. janthinellum FHH1 and $P$. oxalicum FLY4 are potential candidates to be utilized in hydrolyzing the lignocellulosic biomass.

\section{CONCLUSIONS}

1. The fungal strains with high cellulase productions were identified as $P$. janthinellum FHH1 and $P$. oxalicum FLY4. Corn stalk was considered as the optimal carbon source for both strains. Beef extract and peptone were the optimal nitrogen source for $P$. janthinellum FHH1 and P. oxalicum FLY4, respectively.

2. High cellulase activities were obtained in a $\mathrm{pH}$ range of 4.0 to 6.0 and a temperature between 55 and $60{ }^{\circ} \mathrm{C}$ during hydrolysis. A higher $\mathrm{NaCl}$ stability and ILs stability was observed for cellulase obtained from $P$. oxalicum FLY4 than $P$. janthinellum FHH1. 
3. High reducing sugar yields were achieved by enzymatic hydrolysis of ILs-pretreated corn stalk. A combination of ILs pretreatment and cellulase saccharification will have a successful utilization for the degradation of lignocellulosic biomass into value-added products.

\section{ACKNOWLEDGMENTS}

This work was financially supported by Heilongjiang Province Key Laboratory of Cold Region Wetland Ecology and Environment Research (201901), and Young Doctoral Research Initiation Fund Project of Harbin University (HUDF2021110), and Natural Science Foundation of Heilongjiang Province (YQ2020C001).

\section{REFERENCES CITED}

Adsul, M. G., Bastawde, K. B., Varma, A. J., and Gokhale, D. V. (2007). "Strain improvement of Penicillium janthinellum NCIM 1171 for increased cellulase production," Bioresource Technology 98(7), 1467-1473. DOI:

10.1016/j.biortech.2006.02.036

Adsul, M. G., Terwadkar, A. P., Varma, A. J., and Gokhale, D. (2009). "Cellulases from Penicillium janthinellum mutants: Solid-state production and their stability in ionic liquids," BioResources 4(4), 1670-1681. DOI: 10.15376/biores.4.4.1670-1681

Agrawal, R., Satlewal, A., Sharma, B., Mathur, A., Gupta, R., Tuli, D., and Adsul, M. (2017). "Induction of cellulases by disaccharides or their derivatives in Penicillium janthinellum EMS-UV-8 mutant," Biofuels 8(5), 615-622. DOI: 10.1080/17597269.2016.1242692

Baba, Y., Sumitani, J., Tani, S., and Kawaguchi, T. (2015). "Characterization of Aspergillus aculeatus $\beta$-glucosidase 1 accelerating cellulose hydrolysis with Trichoderma cellulase system," AMB Express 5(1), 3. DOI: 10.1186/s13568-0140090-3

Dwivedi, P., Vivekanand, V., Ganguly, R., and Singh, R. P. (2009). "Parthenium sp. as a plant biomass for the production of alkali-tolerant xylanase from mutant Penicillium oxalicum SAUE-3.510 in submerged fermentation," Biomass and Bioenergy 33(4), 581-588. DOI: 10.1016/j.biombioe.2008.09.001

Dashtban, M., and Qin, W. (2012). "Overexpression of an exotic thermotolerant $\beta$ glucosidase in Trichoderma reesei and its significant increase in cellulolytic activity and saccharification of barley straw," Microbial Cell Factories 11(63), 63. DOI: 10.1186/1475-2859-11-63

Fitzpatrick, M., Champagne, P., Cunningham, M. F., and Whitney, R. A. (2010). "A biorefinery processing perspective: Treatment of lignocellulosic materials for the production of value-added products," Bioresource Technology 101(23), 8915-8922. DOI: 10.1016/j.biortech.2010.06.125

Gowthaman, M. K., Krishna, C., and Moo-Young, M. (2001). "Fungal solid state fermentation-an overview," Applied Mycology and Biotechnology 1, 305-352. DOI: 10.1016/S1874-5334(01)80014-9 
Gusakov, A. V., and Sinitsyn, A. P. (2012). "Cellulases from Penicillium species for producing fuels from biomass," Biofuels 3(4), 463-477. DOI: 10.4155/bfs.12.41

Han, H. Y., Geng, X., Zhang, B. X., Meng, J., Liu, X., He, X. M., Liu, Z. G., Gao, Y. F., Liu, D., and Hu, X. M. (2019). "Synthesis of novel functional ionic liquids and their application in biomass," RSC Advances 9(51), 29652-29658. DOI: $10.1039 / \mathrm{c} 9 \mathrm{ra06243b}$

Jatoi, A. S., Abbasi, S. A., Hashmi, Z., Shah, A. K., Alam, M. S., Bhatti, Z. A., Maitlo, G., Hussain, S., Khandro, G. A., Usto, M. A., and Iqbal, A. (2021). "Recent trends and future perspectives of lignocellulose biomass for biofuel production: A comprehensive review," Biomass Conver. Biorefin. DOI: 10.1007/s13399-02101853-8

Jing, L., Zhao, S., Xue, J. L., Zhang, Z., Yang, Q., Xian, L., and Feng, J. X. (2015). "Isolation and characterization of a novel Penicillium oxalicum strain Z1-3 with enhanced cellobiohydrolase production using cellulase-hydrolyzed sugarcane bagasse as carbon source," Industrial Crops and Products 77, 666-675. DOI: 10.1016/j.indcrop.2015.09.052

Kirk, O., Borchert, T. V., and Fuglsang, C. C. (2002). "Industrial enzyme applications," Current Opinion in Biotechnology 13(4), 345-351. DOI: 10.1016/S09581669(02)00328-2

Larsson, S., Cassland, P., and Jönsson, L. J. (2001). "Development of a Saccharomyces cerevisiae strain with enhanced resistance to phenolic fermentation inhibitors in lignocellulose hydrolysates by heterologous expression of laccase," Applied and Environmental Microbiology 67(3), 1163-1170. DOI: 10.1128/AEM.67.3.11631170.2001

Liao, H., Li, S., Wei, Z., Shen, Q., and Xu, Y. (2014). "Insights into high-efficiency lignocellulolytic enzyme production by Penicillium oxalicum GZ-2 induced by a complex substrate," Biotechnology for Biofuels 7(1), 1-17. DOI: 10.1186/s13068014-0162-2

Liao, H., Fan, X., Mei, X., Wei, Z., Raza, W., Shen, Q., and Xu, Y. (2015). "Production and characterization of cellulolytic enzyme from Penicillium oxalicum GZ-2 and its application in lignocellulose saccharification," Biomass and Bioenergy 74, 122-134. DOI: 10.1016/j.biombioe.2015.01.016

Miller, G. L. (1959). "Use of dinitrosalicylic acid reagent for determination of reducing sugar," Analytical Chemistry 31(3), 426-428. DOI: 10.1021/ac60147a030

Oliveira, L. A., Porto, A. L., and Tambourgi, E. B. (2006). "Production of xylanase and protease by Penicillium janthinellum CRC 87M-115 from different agricultural wastes," Bioresource Technology 97(6), 862-867. DOI: 10.1016/j.biortech.2005.04.017

Pandey, A., Soccol, C. R., Nigam, P., and Soccol, V. T. (2000). "Biotechnological potential of agro-industrial residues. I: Sugarcane bagasse," Bioresource Technology 74(1), 69-80. DOI: 10.1016/S0960-8524(99)001 42-X

Papa, G., Feldman, T., Sale, K. L., Adani, F., Singh, S., and Simmons, B. A. (2017). "Parametric study for the optimization of ionic liquid pretreatment of corn stover," Bioresource Technology 241, 627-637. DOI: 10.1016/j.biortech.2017.05.167

Paramjeet, S., Manasa, P., and Korrapati, N. (2018). "Biofuels: Production of fungalmediated ligninolytic enzymes and the modes of bioprocesses utilizing agro-based 
residues," Biocatalysis and Agricultural Biotechnology 14, 57-71. DOI: 10.1016/j.bcab.2018.02.007

Saini, R., Saini, J. K., Adsul, M., Patel, A. K., Mathur, A., Tuli, D., and Singhania, R. R. (2015). "Enhanced cellulase production by Penicillium oxalicum for bio-ethanol application," Bioresource technology 188, 240-246. DOI: 10.1016/j.biortech.2015.01.048

Sharma, B., Agrawal, R., Singhania, R. R., Satlewal, A., Mathur, A., Tuli, D., and Adsul, M. (2015). "Untreated wheat straw: Potential source for diverse cellulolytic enzyme secretion by Penicillium janthinellum EMS-UV-8 mutant," Bioresource Technology 196, 518-524. DOI: 10.1016/j.biortech.2015.08.012

Singhania, R. R., Saini, J. K., Saini, R., Adsul, M., Mathur, A., Gupta, R., and Tuli, D. K. (2014). "Bioethanol production from wheat straw via enzymatic route employing Penicillium janthinellum cellulases," Bioresource Technology 169, 490-495. DOI: 10.1016/j.biortech.2014.07.011

Su, L. H., Zhao, S., Jiang, S. X., Liao, X. Z., Duan, C. J., and Feng, J. X. (2017). "Cellulase with high $\beta$-glucosidase activity by Penicillium oxalicum under solid state fermentation and its use in hydrolysis of cassava residue," World Journal of Microbiology and Biotechnology 33(2), 37. DOI: 10.1007/s11274-016-2200-7

Taha, M., Shahsavari, E., Al-Hothaly, K., Mouradov, A., Smith, A. T., Ball, A. S., and Adetutu, E. M. (2015). "Enhanced biological straw saccharification through coculturing of lignocellulose-degrading microorganisms," Applied Biochemistry and Biotechnology 175(8), 3709-3728. DOI: 10.1007/s12010-015-1539-9

Verma, D., Kanagaraj, A. K., Jin, S. X., Singh, N. D., Kolattukudy, P. E., and Daniell, H. (2010). "Chloroplast-derived enzyme cocktails hydrolyse lignocellulosic biomass and release fermentable sugars," Plant Biotechnology Journal 8(3), 332-350. DOI: 10.1111/j.1467-7652.2009.00486.x

Wood, P. J., Erfle, J. D., and Teather, R. M. (1988). "Use of complex formation between Congo Red and polysaccharides in detection and assay of polysaccharide hydrolases," Methods in Enzymology 160, 59-74. DOI: 10.1016/0076-6879(88)60107-8

Xi, R. P., Qi, Y. Q., Zhang, B. X., He, X. M., Chen, H. S., Gao, Y. F., and Hu, X. M. (2020). "Mutagenesis of Aspergillus aculeatus by ${ }^{60} \mathrm{Co}-\gamma$ irradiation for high production of potential ILs-Tolerant cellulase," BioResources 15(3), 6974-6988. DOI: 10.15376/biores.15.3.6974-6988

Yao, G., Li, Z., Gao, L., Wu, R., Kan, Q., Liu, G., and Qu, Y. (2015). "Redesigning the regulatory pathway to enhance cellulase production in Penicillium oxalicum," Biotechnology for biofuels 8(1), 1-17. DOI: 10.1186/s13068-015-0253-8

Article submitted: July 18, 2021; Peer review completed: September 5, 2021; Revised version received and accepted: November 3, 2021; Published: November 18, 2021. DOI: $10.15376 /$ biores.17.1.355-368 